\title{
Updated fracture incidence rates for the US version of FRAX®
}

\author{
B. Ettinger • D. M. Black • B. Dawson-Hughes • \\ A. R. Pressman $\cdot$ L. J. Melton III
}

Received: 16 March 2009/Accepted: 26 May 2009/Published online: 25 August 2009

(C) The Author(s) 2009. This article is published with open access at Springerlink.com

\begin{abstract}
Summary On the basis of updated fracture and mortality data, we recommend that the base population values used in the US version of FRAX $^{\circledR}$ be revised. The impact of suggested changes is likely to be a lowering of 10 -year fracture probabilities.

Introduction Evaluation of results produced by the US version of FRAX ${ }^{\circledR}$ indicates that this tool overestimates the likelihood of major osteoporotic fracture. In an attempt to correct this, we updated underlying fracture and mortality rates for the model. Methods We used US hospital discharge data from 2006 to calculate annual age- and sex-specific hip fracture rates and age-specific ratios to estimate clinical vertebral fracture rates. To estimate the incidence of any one of four major
\end{abstract}

B. Ettinger · A. R. Pressman

Division of Research, Kaiser Permanente Medical Care Program, Oakland, CA, USA

D. M. Black

Department of Epidemiology \& Biostatistics,

University of California,

San Francisco, CA, USA

B. Dawson-Hughes

Jean Mayer US Department of Agriculture Human Nutrition

Research Center on Aging, Tufts University,

Boston, MA, USA

L. J. Melton III

Division of Epidemiology, College of Medicine, Mayo Clinic,

Rochester, MN, USA

B. Ettinger $(\square)$

156 Lombard Street \#13,

San Francisco, CA 94111, USA

e-mail: doc.ettinger@gmail.com osteoporotic fractures, we first summed these newly derived hip and vertebral fracture estimates with Olmsted County, $\mathrm{MN}$, wrist and upper humerus fracture rates, and then applied 10-20\% discounts for overlap.

Results Compared with rates used in the current FRAX ${ }^{\circledR}$ tool, 2006 hip fracture rates are about 16\% lower, with greatest reductions observed among those below age 65 years; major osteoporotic fracture rates are about one quarter lower, with similar reductions across all ages.

Conclusions We recommend revising the US-FRAX by updating current base population values for hip fracture and major osteoporotic fracture. The impact of these revisions on FRAX ${ }^{\circledR}$ is likely to be lowering of 10 -year fracture probabilities, but more precise estimates of the impact of these changes will be available after these new rates are incorporated into the FRAX ${ }^{\circledR}$ tool.

Keywords Fracture $\cdot$ FRAX $^{\circledR} \cdot$ Risk assessment

\section{Introduction}

Growth of the elderly population will lead to dramatic increases in osteoporosis-related fractures in coming decades [1]. Currently, an estimated 10 million Americans $\geq 50$ years old have osteoporosis according to World Health Organization (WHO) criteria [2], while over 33 million more have "osteopenia" (analogous to "prediabetes"); the total number with low bone mass could reach 61 million by 2020 [3]. Consequently, the estimated 2 million osteoporosis-related fractures in 2005 could exceed 3 million by 2025, with an associated increase in cost from $\$ 16.9$ billion to $\$ 25.3$ billion annually [4]. To significantly reduce future fractures, interventions must be broadly applied because most of the population is at some degree of risk. However, public health 
approaches, though essential [5], are of uncertain benefit [6] or cost-effectiveness [7] and may have unexpected adverse outcomes [8]. Pharmacologic prophylaxis is efficacious [9] but has significant side effects [10-12], and in addition, treating the entire community is unaffordable.

The key is to discriminate the patients at sufficiently high fracture risk from those at lower risk in whom expensive osteoporosis interventions will have limited value. In the past, risk stratification has relied primarily on bone densitometry, which is both insensitive and nonspecific for fracture outcomes [13-16]; however, sensitivity and specificity can be improved simultaneously by increasing the assessment gradient of risk [17]. This is accomplished in the WHO's new fracture prediction algorithm, FRAX ${ }^{\circledR}$, by augmenting bone mineral density (BMD) data with documentation of clinical risk factors in order to predict a patient's 10-year fracture probability [18]. FRAX ${ }^{\circledR}$ now provides the basis for the National Osteoporosis Foundation's (NOF) individualized approach to fracture prevention [19]. It is important for prediction of the fracture probability to be as accurate as possible, and recently, the opportunity has presented itself to improve the data used to calculate a patient's fracture risk in the US version of the FRAX ${ }^{\circledR}$ tool (US-FRAX). This report explains the rationale for these revisions and estimates their impact on results obtained with the fracture tool.

\section{US-FRAX 10-year hip fracture probability}

Since fracture incidence varies by age, sex, race, and geographic region [20], the FRAX $^{\circledR}$ algorithm must be calibrated to each population using local hip fracture and mortality rates. In the case of the USA, the model was calibrated to data on hip fracture incidence from Olmsted County, MN, combined with national death rates.

Hip fracture incidence rates-non-Hispanic whites

In lieu of better data at the time, both the original version of the US-FRAX posted February 2008 and the revision posted October 2008 (www.sheffield.ac.uk/FRAX) were calibrated to hip fracture incidence rates documented for the predominantly white population of Olmsted County during 1989-1991 [21]. Comparably age- and sex-adjusted to the 2000 US white population, the 1989-1991 Olmsted County annual incidence rate for those age 50 years and older was 3.86 per 1,000 , quite similar to the 3.91 per 1,000 figure later reported for US whites for the year 2001 [4]. Using these rates, the US-FRAX reports 10-year hip fracture probability estimates similar to those reported for several European countries. However, the Olmsted County rates were based on relatively small numbers of fracture cases, and these 1989-1991 data are now outdated given evidence that hip fracture incidence rates are declining in the white population of this country [22-25].

In order to obtain more recent and robust data, we updated these hip fracture rates using 2006 hospital discharge data for non-Hispanic white women and men from the Healthcare Cost and Utilization Project (HCUP) Nationwide Inpatient Sample (NIS) that was previously used by Burge et al. [4] to estimate national hip fracture incidence rates for the white population in 2001. The NIS is a random sampling of $20 \%$ of hospital discharges each year. This data set is created by the Agency for Health Care Research and Quality through HCUP and calculates weightings that allow discharge rates to be up-weighted to project rates for the entire US population. The most recent data available to us were for 2006 and include reporting from 38 states. As in previous analyses [4], proximal femur fractures were defined as ICD-9-CM codes $820.0 \times$ (transcervical), $820.2 \times$ (pertrochanteric), and $820.8 \times$ (neck of femur). To be conservative, open fractures were excluded. Moreover, only cases with a primary diagnosis of fracture were included: Any patients with only secondary fracture diagnoses were excluded, as were hospital admissions due to severe trauma (based on E-codes; less than $2 \%$ of the total). Although ten states reported little or no information on race, 24 of the 38 states in 2006 NIS had acceptable or near-complete race reporting, with $0-8 \%$ of hip fracture subjects missing race (most $1-2 \%$ ); four other states had $16-42 \%$ missing race data. Based on race reporting from these 28 states, we derived an equation that predicted the percentage of each state's hip fractures that occurred among whites from the percentage of the white population in that state. The contribution of each state to the equation was weighted by its number of hip fractures. Next, we applied the weighted equation to all hip fractures missing race (about one quarter of the total). We then obtained US Census projections for 2006 and collected denominator numbers of non-Hispanic whites by sex and age; hip fracture incidence rates for this population were then estimated by 5 -year age groups. All programming was done using the NIS-specific macros and the SAS programming language (SAS 9.1, SAS Institute, Cary, NC). A smoothing function from Proc REGLIN in SAS was then applied to the 5-year incidence rates to smooth the data and create single-year of age incidence rates to be used in the US-FRAX algorithm.

The resulting hip fracture incidence rates are shown in Table 1 and in Fig. 1a and b for men and women, respectively. Although overall age- and sex-adjusted rates were similar between Olmsted County in 1989-1991 and NIS in 2006, only 19 hip fracture cases were available to estimate the Olmsted County rates for women age 50 64 years, and only nine cases for men in this age group. Using 2006 NIS data, these estimates were based on several 
Table 1 Estimated

annual hip fracture incidence (per 1,000) comparing current and revised rates
${ }^{a}$ Incidence per 1,000 directly age-adjusted to the 2006 US non-Hispanic white population

${ }^{\mathrm{b}}$ Incidence per 1,000 directly ageand sex-adjusted to the 2006 US non-Hispanic white population

\begin{tabular}{|c|c|c|c|c|}
\hline \multirow[t]{2}{*}{ Age-group } & \multicolumn{2}{|c|}{ Olmsted County, MN, 1989-1991 [21] } & \multicolumn{2}{|c|}{ National Inpatient Sample, 2006} \\
\hline & Rate & No. of fractures & Rate & No. of fractures \\
\hline \multicolumn{5}{|l|}{ Women } \\
\hline $50-54$ & 0.66 & 5 & 0.29 & 2,197 \\
\hline $55-59$ & 0.83 & 5 & 0.57 & 3,992 \\
\hline $60-64$ & 1.65 & 9 & 1.05 & 5,679 \\
\hline $65-69$ & 2.21 & 11 & 2.03 & 8,690 \\
\hline $70-74$ & 2.75 & 12 & 3.94 & 14,578 \\
\hline $75-79$ & 8.61 & 33 & 7.93 & 27,488 \\
\hline $80-84$ & 18.38 & 57 & 14.47 & 42,322 \\
\hline $85+$ & 24.88 & 85 & 26.05 & 82,383 \\
\hline Subtotal & $5.37^{\mathrm{a}}$ & 217 & $4.97^{\mathrm{a}}$ & 187,339 \\
\hline \multicolumn{5}{|l|}{ Men } \\
\hline $50-54$ & 0.40 & 3 & 0.28 & 2,062 \\
\hline $55-59$ & 0.32 & 2 & 0.38 & 2,528 \\
\hline $60-64$ & 0.81 & 4 & 0.66 & 3,333 \\
\hline $65-69$ & 1.89 & 8 & 1.18 & 4,510 \\
\hline $70-74$ & 1.60 & 5 & 2.10 & 6,462 \\
\hline $75-79$ & 5.34 & 12 & 4.02 & 10,355 \\
\hline $80-84$ & 5.97 & 8 & 8.13 & 14,724 \\
\hline $85+$ & 15.01 & 16 & 16.30 & 23,060 \\
\hline Subtotal & $2.10^{\mathrm{a}}$ & 58 & $2.09^{\mathrm{a}}$ & 67,034 \\
\hline Total & $3.86^{\mathrm{b}}$ & 275 & $3.64^{\mathrm{b}}$ & 254,373 \\
\hline
\end{tabular}

thousand events in women and men in these age groups. These vastly larger numbers suggest that the revised estimates will be much more reliable, especially among younger men and women. The 2006 NIS rates for the oldest age group are somewhat greater than the Olmsted County figures, but this likely reflects a shift to older average ages within the $85+$ age group due to secular demographic changes in the underlying population [26]. Finally, the more recent overall 2006 NIS rates are 16\% lower than comparably age- and sex-adjusted NIS rates from 2001 (4.31 per $1,000)$, reflecting the ongoing decline in hip fracture incidence observed nationally [22-25]. US-FRAX will use the 1-year age intervals for hip fracture, a significant improvement in accuracy over the previous 5-year age data (John Kanis, May 11, 2009, personal communication). The major impact of the change in base hip fracture incidence will be among younger women and men, where hip fracture probability estimates could be up to $40 \%$ lower than those currently produced by US-FRAX.

\section{US-FRAX 10-year major osteoporotic fracture probability}

Because hip fractures represent the minority of osteoporotic fractures [29], a focus on hip fractures alone could be misleading for high-risk younger individuals whose 10-year risk relates more to spine and wrist fractures. Consequently, FRAX $^{\circledR}$ also estimates the patient's 10-year likelihood of any one of four major osteoporotic fractures (4 fracture risk: proximal femur, clinical vertebral, distal radius, or proximal humerus fractures), and some revisions in those calculations were indicated as well.

Fracture site-specific incidence rates

In its current implementation, US-FRAX also used 19891991 Olmsted County data for fracture-specific incidence rates [21] and produced age- and sex-specific incidence rates for four fractures by considering them all together and modeling the risk of any one [30] (Table 2). Unlike the USFRAX 10-year hip fracture probabilities, which seem consistent with FRAX $^{\circledR}$ estimates from other countries as well as US cohort studies, the 4-fracture 10-year probabilities produced by US-FRAX are higher than those in other countries and higher than those observed in the Study of Osteoporotic Fractures (SOF; Meghan G. Donaldson, personal communication). Moreover, the ratio of the 10year 4 fracture and hip fracture probability alone was much greater than seen elsewhere. For example, in the current version of US-FRAX, the 4 fracture and hip fracture ratio in 65 -year-old women is $11: 1$, whereas it is only about $6: 1$ in 
a

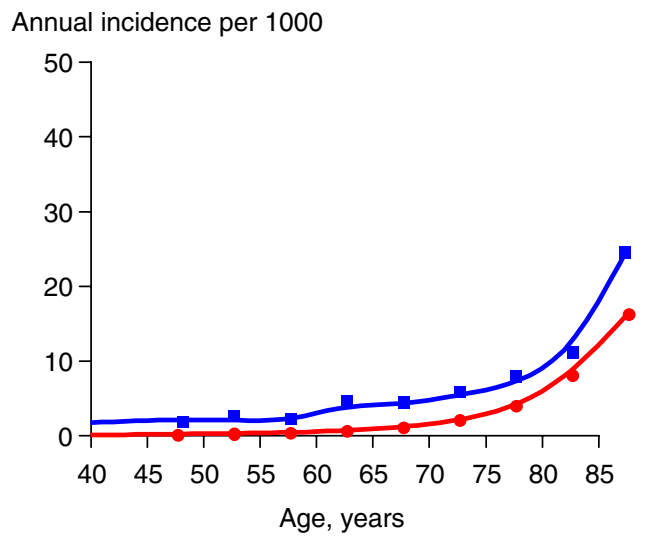

b

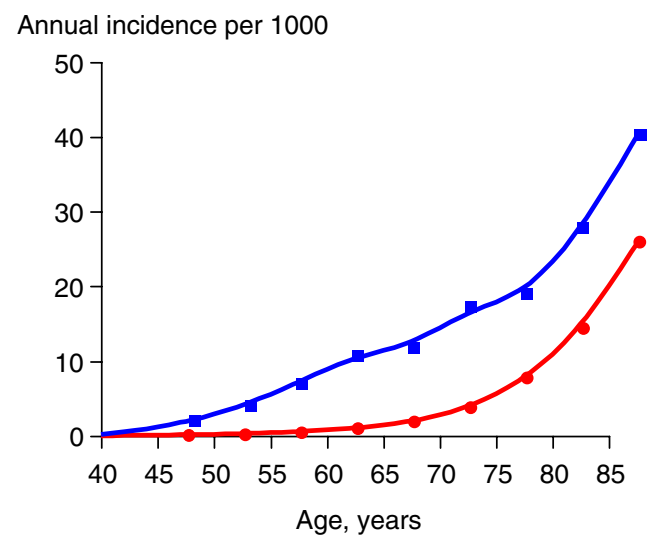

Fig. 1 a, b Comparison of hip fracture incidence rates ( - ) to the incidence of any one of four (hip, spine, forearm, or humerus) major osteoporotic fractures ( $-\boldsymbol{C}$ ) among non-Hispanic white men (a) and non-Hispanic white women (b) by single year of age (smoothed data)

the prospective SOF investigation (unpublished data) and 6.6 in the UK [31].

In order to clarify this discrepancy, a review of the data currently used for the US-FRAX implementation was conducted. The incidence data were compared to cohort studies in the USA and elsewhere and specifically compared to 4 fracture assumptions used in the implementation of FRAX ${ }^{\circledR}$ in other countries. Upon closer inspection, it was determined that the incidence rates for forearm and humerus fractures from Olmsted County were similar to those seen in other studies, and the overall discrepancy in 10 -year 4 fracture probabilities could be attributed primarily to the high incidence of vertebral fractures reported for Olmsted County residents compared to other settings (Table 3). In the Olmsted County analysis, these all were "clinical" vertebral fractures insofar as they were recognized in the course of routine care by the providers of inpatient and outpatient medical care in the community, and all were confirmed on a contemporary radiologist's report [21]. Although the fractures represented discrete events, they were not necessarily first-ever vertebral fractures.
Thus, the overall age- and sex-adjusted (to the 2000 US white population) annual incidence of vertebral fractures in Olmsted County was 4.39 per 1,000 , but this was reduced to 3.89 per 1,000 if only initial vertebral fractures in 1989 1991 were counted. If, however, only first-ever (in a lifetime) vertebral fractures were considered, the incidence rate would be just 1.41 per 1,000 based on community data for 1985-1994 [32]. More importantly, many vertebral fractures in the Olmsted County analysis were diagnosed incidentally, as they came to attention while working up some other problem, including other osteoporotic fractures (one patient in ten in the 1989-1991 study) as seen also by others [33]; clearly, these do not all reflect "symptomatic" vertebral fractures, i.e., painful back prompting radiograph with fracture reading confirmed.

After extensive discussions, it was concluded that there was a need to revise the vertebral fracture incidence rates used in the US-FRAX. Unfortunately, every potential alternative source of data also has important limitations, including restrictions by age and sex or reliance of examinations of study volunteers in cohort studies. Moreover, the lack of a uniform definition and the problem of distinguishing incident from prevalent vertebral fractures are major stumbling blocks [34]. The solution was derived from the previous work of Kanis et al. [30], who used the ratio of clinical vertebral fractures to hip fractures from Malmo, Sweden to estimate clinical vertebral fracture rates for women in the UK implementation of FRAX ${ }^{\circledR}[31]$. We replicated this process and replaced the Olmsted County vertebral fracture rates with estimates based on the ratio of clinical vertebral to hip fracture incidence in the Malmo data, which were then applied to the revised hip fracture rates from the NIS data (see above). As shown in Table 4, this resulted in estimated clinical ( $\sim$ symptomatic) vertebral fracture rates much lower than those US-FRAX employed from Olmsted County.

\section{Overlap among fracture types}

To obtain a more accurate estimate of annual risk for any of the four fractures, it would be of interest to adjust for multiple counting inherent in summing the annual risks for the four individual types of fractures. Adjusting for multiple counting would have decreased the overall Olmsted County rates by $16 \%$ (difference between reported fracture counts and numbers of people with any fracture) [21]. In order to accurately adjust for this overlap, it would be ideal to have population data showing the annual age- and sex-specific incidence for each of the four fracture types separately as well as rates for any one of the four in any one individual. This would allow creation of an age- and sex-specific "discount" to the sum of the 4 fracture rates. An agespecific discount would be ideal, as the overlap is likely to 
Table 2 Comparison of current (Olmsted County, MN) and revised fracture rates (annual incidence per 1,000), along with revised incidence ratios of any one of four major osteoporotic fracture to hip fracture

\begin{tabular}{|c|c|c|c|c|c|c|c|c|c|c|c|c|}
\hline \multirow[t]{2}{*}{$\begin{array}{l}\text { Age } \\
\text { group }\end{array}$} & \multicolumn{2}{|l|}{ Hip } & \multicolumn{2}{|l|}{ Vertebra } & \multicolumn{2}{|l|}{ Humerus } & \multicolumn{2}{|l|}{ Forearm } & \multicolumn{2}{|c|}{$\begin{array}{l}\text { Incidence of major } \\
\text { osteoporotic } \\
\text { fractures }\end{array}$} & \multicolumn{2}{|c|}{$\begin{array}{l}\text { Ratio of } 4 \text { fracture } \\
\text { to hip fracture } \\
\text { alone }\end{array}$} \\
\hline & Current [21] & Revised & Current [21] & Revised & Current [21] & Revised & Current [21] & Revised & Current $^{\mathrm{a}}$ & Revised $^{\mathrm{b}}$ & Current $^{\mathrm{a}}$ & Revised $^{\mathrm{b}}$ \\
\hline \multicolumn{13}{|l|}{ Women } \\
\hline $50-54$ & 0.66 & 0.29 & 2.25 & 0.64 & 0.66 & 0.66 & 2.91 & 2.91 & 5.83 & 4.05 & 8.83 & 13.97 \\
\hline $55-59$ & 0.83 & 0.57 & 2.15 & 1.32 & 1.65 & 1.65 & 4.30 & 4.30 & 8.04 & 7.06 & 9.69 & 12.39 \\
\hline $60-64$ & 1.65 & 1.05 & 3.49 & 1.24 & 1.65 & 1.65 & 8.08 & 8.08 & 13.38 & 10.82 & 8.11 & 10.30 \\
\hline $65-69$ & 2.21 & 2.03 & 6.82 & 2.33 & 1.40 & 1.40 & 8.22 & 8.22 & 15.85 & 11.88 & 7.17 & 5.85 \\
\hline $70-74$ & 2.75 & 3.94 & 11.67 & 4.73 & 3.43 & 3.43 & 8.24 & 8.24 & 22.18 & 17.29 & 8.07 & 4.39 \\
\hline $75-79$ & 8.61 & 7.93 & 15.66 & 5.23 & 2.44 & 2.44 & 8.35 & 8.35 & 28.05 & 19.16 & 3.26 & 2.42 \\
\hline $80-84$ & 18.38 & 14.47 & 25.79 & 6.22 & 5.48 & 5.48 & 8.70 & 8.70 & 46.68 & 27.90 & 2.54 & 1.93 \\
\hline $85+$ & 24.88 & 26.06 & 31.32 & 10.95 & 4.98 & 4.98 & 8.49 & 8.49 & 55.74 & 40.38 & 2.24 & 1.55 \\
\hline \multicolumn{13}{|l|}{ Men } \\
\hline $50-54$ & 0.40 & 0.28 & 0.94 & 0.43 & 0.27 & 0.27 & 1.47 & 1.47 & 2.77 & 2.21 & 6.93 & 7.89 \\
\hline $55-59$ & 0.32 & 0.38 & 1.60 & 0.46 & 0.48 & 0.48 & 0.64 & 0.64 & 2.74 & 1.76 & 8.56 & 4.63 \\
\hline $60-64$ & 0.81 & 0.66 & 0.81 & 1.78 & 0.81 & 0.81 & 1.41 & 1.41 & 3.46 & 4.19 & 4.27 & 6.35 \\
\hline $65-69$ & 1.89 & 1.18 & 4.97 & 1.14 & 1.42 & 1.42 & 0.95 & 0.95 & 7.85 & 3.99 & 4.15 & 3.38 \\
\hline $70-74$ & 1.60 & 2.10 & 4.15 & 2.14 & 1.60 & 1.60 & 0.64 & 0.64 & 6.79 & 5.51 & 4.24 & 2.62 \\
\hline $75-79$ & 5.34 & 4.02 & 6.68 & 3.50 & 1.34 & 1.34 & 0.45 & 0.45 & 11.74 & 7.45 & 2.20 & 1.85 \\
\hline $80-84$ & 5.97 & 8.13 & 15.67 & 3.58 & 0.75 & 0.75 & 1.49 & 1.49 & 19.10 & 11.16 & 3.20 & 1.37 \\
\hline $85+$ & 15.01 & 16.30 & 25.33 & 12.39 & 1.88 & 1.88 & 0.94 & 0.94 & 34.53 & 25.21 & 2.30 & 1.55 \\
\hline
\end{tabular}

${ }^{a}$ The risk of any one of four major osteoporotic fractures (proximal femur, clinical vertebral, proximal humerus, and distal radius) calculated from the sum of risks for 4 individual fracture types, from Olmstead County, MN [21], after overlap discount applied (see text)

${ }^{\mathrm{b}}$ The sum of revised risks of any one of four major osteoporotic fractures, after overlap discount applied (see text)

increase with age as the absolute incidence of fractures increases. However, there is no perfect source of such data in the USA to estimate this discount. From Malmo, Kanis et al. [30] present 10-year rates of each of the four fractures as

Table 3 Comparison of annual incidence (per 1,000) of "clinical" spine fractures in women from several studies

Age group Olmsted County, MN [21] Malmo, Sweden [32] SOF $^{\mathrm{a}}$

\begin{tabular}{lrrc}
\hline $50-54$ & 2.25 & 1.17 & - \\
$55-59$ & 2.15 & 1.27 & - \\
$60-64$ & 3.49 & 2.12 & - \\
$65-69$ & 6.82 & 3.29 & 2.73 \\
$70-74$ & 11.67 & 5.83 & 2.61 \\
$75-79$ & 15.66 & 7.61 & 3.31 \\
$80-84$ & 25.79 & 7.70 & 5.61 \\
$85-89$ & 31.32 & 12.63 & 4.36 \\
\hline
\end{tabular}

Note that each study defines clinical vertebral fractures differently and that the data from Malmo, Sweden and the Study of Osteoporotic Fractures (SOF) relate to symptomatic vertebral fractures only, i.e., painful back prompting radiograph with fracture reading confirmed

${ }^{\mathrm{a}}$ Unpublished data well as the 10-year modeled rate of "any one of the four." This data set included both men and women in 5-year age groups 45 years and older and has served in the past as the FRAX $^{\circledR}$ adjustment for overlap (John Kanis, March 2, 2009 , personal communication). A second source to verify this adjustment has been provided by the SOF, a cohort study of US women over age 65 years. Utilizing the SOF data, we were able to perform an analysis comparing the 10 -year incidence rates of each of the four fracture types to the 10-year incidence of any one of the four and thus were able to calculate a discount rate, albeit only for older women. Comparing the two results, we derived the discount percentages shown in Table 5. For Malmo data, the ratio of the incidence of any of the four to the sum of the four varies from 0.87 (13\% over counting using the "sum") in age group 50-54 to 0.74 (26\% over counting) in age group 75-79 years. The Malmo estimates are based on statistical models, but the empirical comparison of annual risk from SOF (Table 5) shows similar "discounts" for over counting of $9-18 \%$ among women over age 65 years. Based on these two data sources, in order to estimate the annual risk for any of the four fractures that is adjusted for overlap, the sum of the four should be discounted by $10 \%$ 
Table 4 Annual incidence of clinical vertebral and hip fractures (per 1,000) and their ratios in Malmo, Sweden, applied to the National Inpatient Sample (NIS) 2006 hip fracture rates, to estimate the annual incidence of clinical vertebral fractures (per 1,000) in the US

\begin{tabular}{|c|c|c|c|c|c|c|c|}
\hline \multirow[t]{2}{*}{ Age group } & \multicolumn{5}{|l|}{ Malmo [32] } & \multicolumn{2}{|l|}{ US-FRAX } \\
\hline & $\begin{array}{l}\text { Vertebral fracture } \\
\text { incidence }\end{array}$ & $\div$ & $\begin{array}{l}\text { Hip fracture } \\
\text { incidence }\end{array}$ & $=$ & $\begin{array}{l}\text { Vertebral/hip } \\
\text { fracture ratio }\end{array}$ & $\begin{array}{l}\text { NIS } 2006 \text { hip } \\
\text { fracture incidence }\end{array}$ & $\begin{array}{l}\text { Estimated vertebral } \\
\text { fracture incidence }\end{array}$ \\
\hline \multicolumn{8}{|l|}{ Women } \\
\hline $50-54$ & 1.17 & & 0.53 & & 2.21 & 0.29 & 0.64 \\
\hline $55-59$ & 1.27 & & 0.55 & & 2.31 & 0.57 & 1.32 \\
\hline $60-64$ & 2.12 & & 1.80 & & 1.18 & 1.05 & 1.24 \\
\hline $65-69$ & 3.29 & & 2.86 & & 1.15 & 2.03 & 2.33 \\
\hline $70-74$ & 5.83 & & 4.86 & & 1.20 & 3.94 & 4.73 \\
\hline $75-79$ & 7.61 & & 11.51 & & 0.66 & 7.93 & 5.23 \\
\hline $80-84$ & 7.70 & & 17.99 & & 0.43 & 14.47 & 6.22 \\
\hline $85-89$ & 12.63 & & 29.73 & & 0.42 & 26.06 & 10.95 \\
\hline \multicolumn{8}{|l|}{ Men } \\
\hline $50-54$ & 1.35 & & 0.87 & & 1.55 & 0.28 & 0.43 \\
\hline $55-59$ & 1.02 & & 0.85 & & 1.20 & 0.38 & 0.46 \\
\hline $60-64$ & 1.91 & & 0.71 & & 2.69 & 0.66 & 1.78 \\
\hline $65-69$ & 1.73 & & 1.78 & & 0.97 & 1.18 & 1.14 \\
\hline $70-74$ & 2.85 & & 2.80 & & 1.02 & 2.10 & 2.14 \\
\hline $75-79$ & 4.95 & & 5.68 & & 0.87 & 4.02 & 3.50 \\
\hline $80-84$ & 5.60 & & 12.67 & & 0.44 & 8.13 & 3.58 \\
\hline $85-89$ & 11.08 & & 14.49 & & 0.76 & 16.30 & 12.39 \\
\hline
\end{tabular}

${ }^{\text {a }}$ Product of vertebral/hip fracture ratio times NIS 2006 hip fracture incidence

in those under $65,15 \%$ in those $65-74$, and $20 \%$ in those age 75 years and over. We applied this discount to derive annual 4 fracture incidence rates (both for current and revised incidence sums), which are delineated in Table 2 and Fig. 1a and b.

Table 5 Comparison of results obtained from calculating risk of any one of four major osteoporotic fractures among postmenopausal white women by either summing rates of four individual types of fracture or

Malmo 10-year risk [32]

\begin{tabular}{lll}
\hline Age $\quad$ Any of $4 \quad$ Sum of 4 & $\begin{array}{l}\text { Ratio of "any" to sum } \\
\text { (and implied discount to sum) }\end{array}$
\end{tabular}

\section{Mortality rates}

The FRAX ${ }^{\circledR}$ model also requires age-specific mortality rates. Mortality data are important because the risk of death competes with the risk of fracture. Increased life

by measuring the risk of any one of the four types, comparing data from Malmo, Sweden, with prospective data from the Study of Osteoporotic Fractures (SOF)

SOF 10-year risk ${ }^{\mathrm{a}}$

\begin{tabular}{lll}
\hline Age $\quad$ Any of $4 \quad$ Sum of 4 & $\begin{array}{l}\text { Ratio of "any" to sum } \\
\text { (and implied discount to sum) }\end{array}$
\end{tabular}

\begin{tabular}{rrrlllll}
\hline 50 & 6.0 & 6.9 & $0.87(13 \%)$ & & & & \\
55 & 7.8 & 9.0 & $0.87(13 \%)$ & & & & \\
60 & 10.6 & 12.9 & $0.82(18 \%)$ & $65-69$ & 12.9 & 14.29 & $0.91(9 \%)$ \\
65 & 14.3 & 18.1 & $0.79(21 \%)$ & $70-74$ & 17.3 & 20.13 & $0.86(14 \%)$ \\
70 & 18.9 & 24.8 & $0.76(24 \%)$ & $75-79$ & 24.24 & 27.54 & $0.88(12 \%)$ \\
75 & 22.9 & 30.8 & $0.74(26 \%)$ & $80-84$ & 26.45 & 32.16 & $0.82(18 \%)$ \\
80 & 26.5 & 35.3 & $0.75(25 \%)$ & 285 & 34.53 & 38.74 & $0.89(11 \%)$ \\
85 & 27.0 & 35.2 & $0.77(24 \%)$ & & & \\
\hline 90 & 21.4 & 27.5 & $0.78(22 \%)$ & & & \\
\hline
\end{tabular}

Discount is the estimated decrease in the sum of the four due to overlap in individuals suffering more than one type of fracture

${ }^{a}$ Study of Osteoporotic Fractures: unpublished data 
expectancy in the years since WHO last incorporated death rates would have the effect of increasing estimated 10-year fracture likelihood, particularly among older age groups. US-FRAX used age-, sex-, and race-specific death rates for the US population in 2001 [27], but final mortality rates for 2004 are now available [28]. For the non-Hispanic white population, the age-adjusted rates are $5-6 \%$ lower than 2001 . This corresponds to approximately six extra months of life expectancy at age 50 years and would have the effect of slightly increasing estimated 10year fracture risk in the older age groups.

\section{Effect of revised assumptions for US-FRAX}

The results of these revisions are summarized in Table 6 , which compares the current rates used in US-FRAX (based on the sum of the four individual fracture types from Olmsted County) to the newly derived four-fracture rates based on the steps described above. The revised base annual four-fracture rates are lower, and this should result in lower US-FRAX 10-year four-fracture probability estimates. Indeed, an average one-third reduction in four-fracture risk can be expected in both women and men of all ages.

This revision of the US-FRAX incidence rates should also mean that the absolute likelihood of four fractures for US non-Hispanic white women will be closer to the percentages obtained using FRAX ${ }^{\circledR}$ for European countries. This was evaluated by comparing the four-fracture/hip fracture ratios (for 10-year probability) from these countries to the ratio of annual risk of these categories of fractures in the proposed revision. Thus, Table 6 also shows the 10 -year four-fracture/hip fracture ratio for different ages calculated from FRAX ${ }^{\circledR}$ online tables for a woman with body mass index (BMI) of 25, without clinical risk factors, and with no BMD value. The ratios across Europe are quite similar, while the US ratios based on the October 2008 US-FRAX tool are considerably higher. Judging from our revised annual four-fracture and hip fracture incidence rates, it is likely that the revised US-FRAX will provide results more consistent with those of other countries.

\section{Discussion}

Since FRAX ${ }^{\circledR}$ was adapted for application in the USA some years ago, newer and more robust fracture incidence and mortality rates have become available. In particular, we feel it highly advantageous to use recent hip fracture incidence rates, which have the further advantage of being based on more robust national data. These rates are lower than those used previously in the US-FRAX, in part reflecting ongoing secular trends in hip fracture occurrence. Likewise, life expectancy is improving in this population as documented in the updated mortality rates described. In lieu of unequivocal data on vertebral fracture, we indirectly estimated symptomatic vertebral fractures. Although it would be preferable to have direct documentation of ageand sex-specific incidence rates for the first of any one of the four major osteoporotic fractures, this was not possible. Instead, we explored the potential overlap of each of the four major osteoporotic fractures using the new individual rates of the four fracture types from our current analyses. Our overlap analyses should be considered theoretical exercises since FRAX ${ }^{\circledR}$ will apply its own Malmo-based

Table 6 Comparison of ratios of 10-year 4 fracture probability to 10-year hip fracture probability alone obtained from current FRAX ${ }^{\circledR}$ (available on web site, January 2009)

\begin{tabular}{|c|c|c|c|c|c|c|c|}
\hline \multirow[t]{2}{*}{ Country } & \multicolumn{7}{|c|}{ Age, years } \\
\hline & 50 & 55 & 60 & 65 & 70 & 75 & 80 \\
\hline \multicolumn{8}{|c|}{ Estimates from FRAX ${ }^{\mathbb{R}^{\mathrm{a}}}$ (10-year risk) } \\
\hline US current ${ }^{\mathrm{b}}$ & 16 & 13 & 11 & 11 & 6.2 & 4.2 & 3.5 \\
\hline Sweden & 11 & 9.0 & 6.3 & 4.8 & 3.3 & 2.4 & 2.1 \\
\hline UK & 18 & 12 & 8.6 & 6.6 & 4.8 & 3.1 & 2.4 \\
\hline Italy & 16 & 9.0 & 6.7 & 5.1 & 3.3 & 2.4 & 2.1 \\
\hline France & 12 & 9.3 & 6.6 & 5.1 & 3.5 & 2.5 & 2.3 \\
\hline Spain & 14 & 10 & 6.0 & 4.6 & 3.5 & 2.5 & 2.3 \\
\hline \multicolumn{8}{|c|}{ Based on proposed revision to US incidence rates (annual) } \\
\hline US revised & 14 & 12 & 10 & 5.9 & 4.4 & 2.4 & 1.9 \\
\hline
\end{tabular}

The table also compares the current US ratios with estimates of ratios that might be expected based on revised annual US incidence rates

${ }^{\text {a }}$ From FRAX ${ }^{\circledR}$ tables for white women, without BMD, BMI $=25$, and no risk factors

${ }^{\mathrm{b}}$ Calculated from the October 2008 version of US FRAX, for white women, without BMD, BMI=25, and no risk factors 
[30] internal adjustment to account for overlap (John Kanis, March 2, 2009, personal communication).

Currently, FRAX ${ }^{\circledR}$ uses race/ethnicity offsets relative to non-Hispanic whites to estimate fracture probabilities among US minorities. Our current analyses deal with nonHispanic whites only because fracture data available to us on non-whites were less precise and less accurate. It would be desirable and may be possible in the future to derive more accurate racial offsets or to directly estimate risk in non-whites, not only for hip fractures but also for the other major osteoporotic fractures.

The implications of these incidence rate revisions will need to be considered in several respects. Among younger persons (below age 65 years), 10-year hip fracture probability results will decline and could be up to $40 \%$ lower than those produced by the current US-FRAX. However, the decline in risk among younger subjects is applied to a low starting hip fracture probability. Among the oldest men and women, the revisions could work in the opposite direction, increasing their hip fracture estimates because annual base fracture rates are either unchanged or increased while there would be declining competition from death. The proposed changes in the major osteoporotic fracture rates will systematically lower the 10-year likelihood across all age groups. A more precise estimate of the impact of these revisions on 10-year fracture probability scores will be available once these revised annual rates have been incorporated into US-FRAX.

For those with osteopenia, the NOF guide recommends that treatment should be considered if the 10 -year probability of hip fracture is $3 \%$ or more or if the major osteoporotic fracture probability is $20 \%$ or more [19]. These thresholds were derived from a published costeffectiveness analysis [35]. The pending changes in USFRAX will likely alter the proportions of men and women considered eligible for treatment [27]. However, we do not anticipate that the proposed revisions will affect the size of the treatment-eligible pool to a great extent for several reasons. First, the segment of the population expected to show the greatest decline in 10-year hip fracture probabilities, young men and women, was already at very low average risk and far below the NOF treatment threshold. Nonetheless, some high-risk individuals in this group will undoubtedly fall below the threshold as a result of this change. Second, the majority of elderly men and women will be eligible for treatment based on other criteria (e.g., hip or vertebral fracture or T-score at or below -2.5) [36]. Finally, if proposed changes lower the 10-year likelihood of a major osteoporotic fracture in all age groups and move significant numbers of people below the NOF $20 \%$ threshold, the impact on overall osteoporosis treatment eligibility is expected to be modest because an important driver of treatment eligibility by US-FRAX is the 10-year hip fracture probability [27]. In summary, we do not expect upcoming changes in US-FRAX to dramatically affect the number of individuals who are eligible for treatment. Nonetheless, it will be important to examine the issue in a more quantitative way. After the proposed changes are incorporated into US-FRAX, this will be done in the form of an updated cost-effectiveness analysis and a reassessment of the proportions of the population who would be eligible for treatment.

FRAX $^{\circledR}$ is a dynamic tool and one that can be expected to undergo further updates and modifications in the future. Although this may cause discontinuity in the management of some individual patients, periodic revision will be necessary in order to predict future risk accurately in the context of expected ongoing changes in the US fracture incidence and mortality rates.

Acknowledgement The authors would like to thank Lisa Palermo and Lily Lui for statistical and analytic effort, Meghan Donaldson and Thuy Le for providing SOF fracture analyses, William Leslie, John Kanis and Eugene McCloskey for helpful advice, and Mary Roberts for help in preparing the manuscript. Dr. Black's work on this project was supported by a grant from the Marcled Foundation, San Francisco. This work was supported by Kaiser Permanente Medical Care Program, Oakland, CA, as well as research grant AG04875 from the National Institutes of Health, US Public Health Service.

Conflicts of interest None.

Open Access This article is distributed under the terms of the Creative Commons Attribution Noncommercial License which permits any noncommercial use, distribution, and reproduction in any medium, provided the original author(s) and source are credited.

\section{References}

1. USDHHS (2004) Bone health and osteoporosis: a report of the surgeon general. US Department of Health and Human Services, Rockville

2. Kanis JA, Melton LJ III, Christiansen C et al (1994) The diagnosis of osteoporosis. J Bone Miner Res 9:1137-1141

3. NOF (2002) America's bone health: the state of osteoporosis and low bone mass in our nation. National Osteoporosis Foundation, Washington

4. Burge R, Dawson-Hughes B, Solomon DH et al (2007) Incidence and economic burden of osteoporosis-related fractures in the United States, 2005-2025. J Bone Miner Res 22:465-475

5. USDHHS (2004) Chapter 1. A public health approach to promote bone health. Bone health and osteoporosis: a report of the surgeon general. US Department of Health and Human Services, Rockville, pp 3-15

6. Nieves JW, Barrett-Connor E, Siris ES et al (2008) Calcium and vitamin $\mathrm{D}$ intake influence bone mass, but not short-term fracture risk, in Caucasian postmenopausal women from the National Osteoporosis Risk Assessment (NORA) study. Osteoporos Int 19:673-679

7. Rizzoli R, Boonen S, Brandi ML et al (2008) The role of calcium and vitamin D in the management of osteoporosis. Bone 42:246-249 
8. Bolland MJ, Barber PA, Doughty RN et al (2008) Vascular events in healthy older women receiving calcium supplementation: randomised controlled trial. BMJ 336:262-266

9. MacLean C, Newberry S, Maglione M et al (2008) Systematic review: comparative effectiveness of treatments to prevent fractures in men and women with low bone density or osteoporosis. Ann Intern Med 148:197-213

10. Biswas PN, Wilton LV, Shakir SA (2003) Pharmacovigilance study of alendronate in England. Osteoporos Int 14:507-514

11. Rosen CJ (2005) Clinical practice. Postmenopausal osteoporosis. N Engl J Med 353:595-603

12. Khosla S, Burr D, Cauley J et al (2007) Bisphosphonateassociated osteonecrosis of the jaw: report of a task force of the American Society for Bone and Mineral Research. J Bone Miner Res 22:1479-1491

13. Stone KL, Seeley DG, Lui LY et al (2003) BMD at multiple sites and risk of fracture of multiple types: long-term results from the Study of Osteoporotic Fractures. J Bone Miner Res 18:1947-1954

14. Schuit SC, van der Klift M, Weel AE et al (2004) Fracture incidence and association with bone mineral density in elderly men and women: the Rotterdam Study. Bone 34:195-202

15. Siris ES, Chen YT, Abbott TA et al (2004) Bone mineral density thresholds for pharmacological intervention to prevent fractures. Arch Intern Med 164:1108-1112

16. Cranney A, Jamal SA, Tsang JF et al (2007) Low bone mineral density and fracture burden in postmenopausal women. CMAJ 177:575-580

17. De Laet C, Oden A, Johansson H et al (2005) The impact of the use of multiple risk indicators for fracture on case-finding strategies: a mathematical approach. Osteoporos Int 16:313318

18. Kanis JA; on behalf of the World Health Organization Scientific Group (2007) Assessment of osteoporosis at the primary healthcare level. Technical Report. World Health Organization Collaborating Centre for Metabolic Bone Diseases, University of Sheffield, UK. Printed by the University of Sheffield

19. Dawson-Hughes B, Lindsay R, Khosla S et al (2008) Clinician's guide to prevention and treatment of osteoporosis. National Osteoporosis Foundation, Washington DC

20. Cummings SR, Melton LJ (2002) Epidemiology and outcomes of osteoporotic fractures. Lancet 359:1761-1767

21. Melton LJ III, Crowson CS, O'Fallon WM (1999) Fracture incidence in Olmsted County, Minnesota: comparison of urban with rural rates and changes in urban rates over time. Osteoporos Int 9:29-37

22. Melton LJ III, Kearns AE, Atkinson EJ et al (2009) Secular trends in hip fracture incidence and recurrence. Osteoporos Int 20:687-694

23. Zingmond DS, Melton LJ III, Silverman SL (2004) Increasing hip fracture incidence in California Hispanics, 1983 to 2000. Osteoporos Int 15:603-610

24. Hiebert R, Aharonoff GB, Capla EL et al (2005) Temporal and geographic variation in hip fracture rates for people aged 65 or older, New York State, 1985-1996. Am J Orthop 34:252-255

25. Gehlbach SH, Avrunin JS, Puleo E (2007) Trends in hospital care for hip fractures. Osteoporos Int 18:585-591

26. Melton LJ III, Therneau TM, Larson DR (1998) Long-term trends in hip fracture prevalence: the influence of hip fracture incidence and survival. Osteoporos Int 8:68-74

27. Dawson-Hughes B, Tosteson AN, Melton LJ III et al (2008) Implications of absolute fracture risk assessment for osteoporosis practice guidelines in the USA. Osteoporos Int 19:449-458

28. Kung H-C, Hoyert DL, Xu J et al (2007) Deaths: preliminary data for 2005. National Center for Health Statistics Health E-Stats, September

29. Delmas PD, Marin F, Marcus R et al (2007) Beyond hip: importance of other nonspinal fractures. Am J Med 120:381-387

30. Kanis JA, Johnell O, Oden A et al (2000) Long-term risk of osteoporotic fracture in Malmo. Osteoporos Int 11:669-674

31. Kanis JA, Johnell O, Oden A et al (2008) FRAX and the assessment of fracture probability in men and women from the UK. Osteoporos Int 19:385-397

32. Melton LJ III, Atkinson EJ, Cooper C et al (1999) Vertebral fractures predict subsequent fractures. Osteoporos Int 10:214-221

33. Gallacher SJ, Gallagher AP, McQuillian C et al (2007) The prevalence of vertebral fracture amongst patients presenting with non-vertebral fractures. Osteoporos Int 18:185-192

34. Melton LJ III, Kallmes DF (2006) Epidemiology of vertebral fractures: implications for vertebral augmentation. Acad Radiol 13:538-545

35. Tosteson AN, Melton LJ III, Dawson-Hughes B et al (2008) Costeffective osteoporosis treatment thresholds: the United States perspective. Osteoporos Int 19:437-447

36. Donaldson MG, Cawthon PM, Lui LY et al (2009) Estimates of the proportion of older white women who would be recommended for pharmacologic treatment by the new U.S. National Osteoporosis Foundation Guidelines. J Bone Miner Res 24:675-680 